\title{
Stem cell and regenerative medicine
}

\section{industry highlights}

\section{September 1, 2011-August 31, 2012}

\section{BUSINESS DEVELOPMENT}

\section{"Winning on multiple fronts: Cellular Dynamics International}

Cellular Dynamics International, WI, USA (www.cellulardynamics.com), continued its domination in the area of induced pluripotent stem cells. In addition to its portfolio of iCell ${ }^{\circledR}$ products, human-induced pluripotent stem cell-derived cardiomyocyes, neurons, hepatocytes and endothelial cells, the company launched the new service MyCell ${ }^{\mathrm{TM}}$. MyCell is offering cell reprogramming, genetic engineering and cell differentiation from customers' samples. Cells from a variety of tissue sources can be reprogrammed with genome nonintegrating episomal vectors under feeder-free conditions.

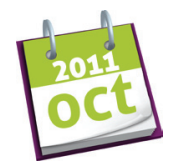

In October 2011, the company was named as the overall Gold winner in The Wall Street Journal Technology Innovation Awards by a panel of independent judges among 605 contestants in 16 categories.

\section{" The thunder from Down Under: Mesoblast}

Following acquisition of the USA company Angioblast and a strategic alliance with Cephalon, now wholly owned by Israel-based Teva Pharmaceutical Industries; www.tevapharm.com), Australia-based Mesoblast (www.mesoblast.com) has strengthened its position even further.

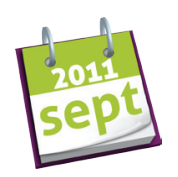

\begin{abstract}
In September 2011, Mesoblast formed a strategic alliance with Lonza for clinical and long-term commercial production of Mesoblast's allogeneic adult stem cell products. The alliance will provide Mesoblast with significant commercial advantages, including certainty of capacity to meet long-term global supply of its proprietary mesenchymal precursor cell products; a purpose-built manufacturing facility to be built by Lonza exclusively for Mesoblast and exclusive access to Lonza's cell therapy facilities in Singapore.
\end{abstract}

Mesoblast has been granted approval to conduct clinical trials of adult stem cell therapies for a number of conditions, including congestive heart failure, heart attacks, spinal fusion and bone marrow regeneration. The company is progressing various products towards Phase III trials.

Dusko Ilic, Human Embryonic Stem Cell Laboratories, Guy's Assisted Conception Unit, Division of Women's Health, King's College London School of Medicine; dusko.ilic@kcl.ac.uk 


\title{
CLINICAL TRIALS
}

\author{
" Making history
}

Advanced Cell Technology's (MA, USA; www.advancedcell.com) clinical trials in Stargradt's and age-related macular degeneration so far look to be a success. Preliminary data published in the Lancet in January 2012 demonstrated the safety of human embryonic stem (hES) cellderived retinal pigment epithelial (RPE) cells for the treatment of one patient with Stargradt disease and one with dry age-related macular degeneration. No abnormal proliferation of the cells, no tumor formation or any other adverse effects were noted after the transplantation. Visual improvement was also noted. Less than a year since the first two patients were injected with 50,000 RPE cells in one eye at the Jules Stein Eye Institute at the University of California, Los Angeles (www.jsei.org), the first cohort of US patients with d $\mathrm{r}$ y age-related macular degeneration was completed.
The promising preliminary results from the first cohort have positioned the Company well as they entered the second cohort and higher dosage in this landmark clinical trial. The first patient of the second cohort was administered 100,000 RPE cells at Wills Eye Institute in Philadelphia (PA, USA; www.willseye.org) on August 12012.

In parallel, the second and the third patients with Stargradt's disease of the first cohort in European clinical trials were treated at Moorfields Eye Hospital in London (UK). The Phase I/II trial is designed to determine the safety and tolerability of hESC-derived RPE cells following subretinal transplantation in patients with Stargradt's disease at 12 months, the study's primary end point. It will involve a total of 12 patients, with cohorts of three patients each in an ascending dosage format $(50,000-200,000)$. It is similar in design to the US trial for Stargradt's disease that was initiated in July 2011.

Additional information about these clinical trials can also be found at www. clinicaltrials.gov (ID: NCT01345006, NCT01344993 and NCT01469832). 


\section{॥ Into the clinic}

In May 2012, a human mesenchymal stem cell therapy product Prochymal ${ }^{\circledR}$ (remestemcel-L), produced by Osiris Therapeutics, MD, USA (www.osiris. com) received market authorization from Health Canada for the treatment of acute graft-versus-host disease (GVHD) in children. New Zealand's medical regulatory agency, Medsafe, voiced their approval a few weeks later. It is also the only stem cell therapeutic currently designated by the US FDA as both an orphan drug and fast track product.

\section{Nearly 10,000 doses \\ can be manufactured from \\ a single donation using \\ proprietary isolation and amplification procedures. 9}

Prochymal's stem cells are derived from the bone marrow of prescreened healthy donors aged $18-30$ years. The health of the donors is monitored for up to 5 years after donation to further ensure their health status. The freshly isolated human mesenchymal stem cells from the bone marrow aspirate are subjected to initial quality control testing for the stem cell potential and safety of the donor before further manufacturing. The in-process intermediate then undergoes further manufacturing to yield a final product, which must pass stringent criteria before release and distribution. Nearly 10,000 doses can be manufactured from a single donation using proprietary isolation and amplification procedures. The Company has 49 issued US patents, each having one or more foreign counterparts.

Prochymal is currently being evaluated in clinical trials for the following indications: treatmentresistant, moderate-to-severe Crohn's disease (www.clinicaltrials.gov ID: NCT00482092), steroid-refractory acute GVHD (ID:NCT00366145 and NCT00759018) and, in combination with corticosteroids, newly diagnosed acute GVHD (ID:NCT00562497). All four are PhaseIIIclinicaltrials. Treatmentof recently diagnosed Type 1 diabetes mellitus (ID:NCT00690066) and acute myocardial infarction (ID:NCT00877903) are Phase II clinical trials. All clinical trials are ongoing in multiple centers throughout USA, and some of them also in Canada, Europe and Australia. In addition, Osiris has partnered with Genzyme Corporation, MA, USA (www.genzyme. com), which was acquired in 2011 by French giant Sanofi (www.sanofi.com), to develop Prochymal as a medical countermeasure to nuclear terrorism and other radiological emergencies.

Osiris's division of biosurgery also made an important milestone. The Center for Medicare \& Medicaid Services (CMS; www. cms.gov), for Americans 65 years and older, issued a transitional pass-through status with CCodes being designated for Grafix $^{\circledR}$. CMS also issued a preliminary positive decision for the assignment of permanent Healthcare Common Procedure Coding System Q-codes for Grafix. The codes will assist in facilitating reimbursement when Grafix products are used to treat Medicare patients with acute and chronic wounds, especially diabetic foot ulcers, in the hospital outpatient department and ambulatory surgical center settings. This coverage decision will boost investor confidence in Osiris's portfolio of stem cell-based therapeutics.

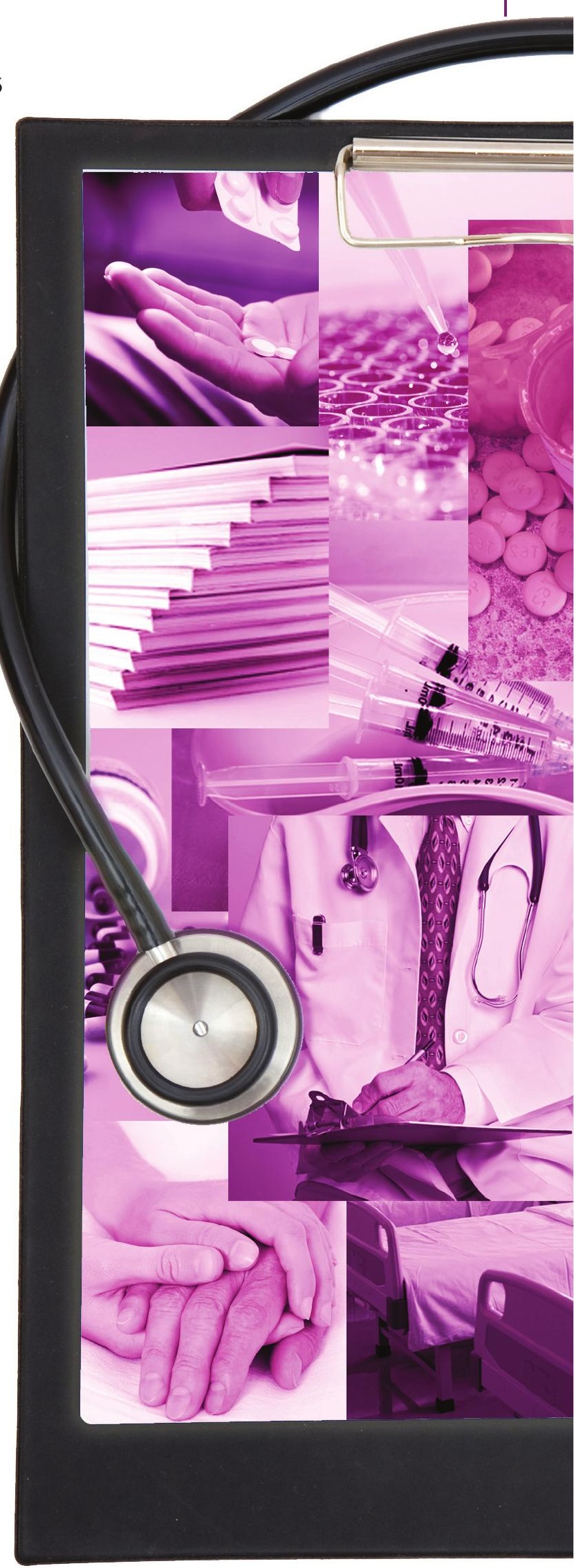




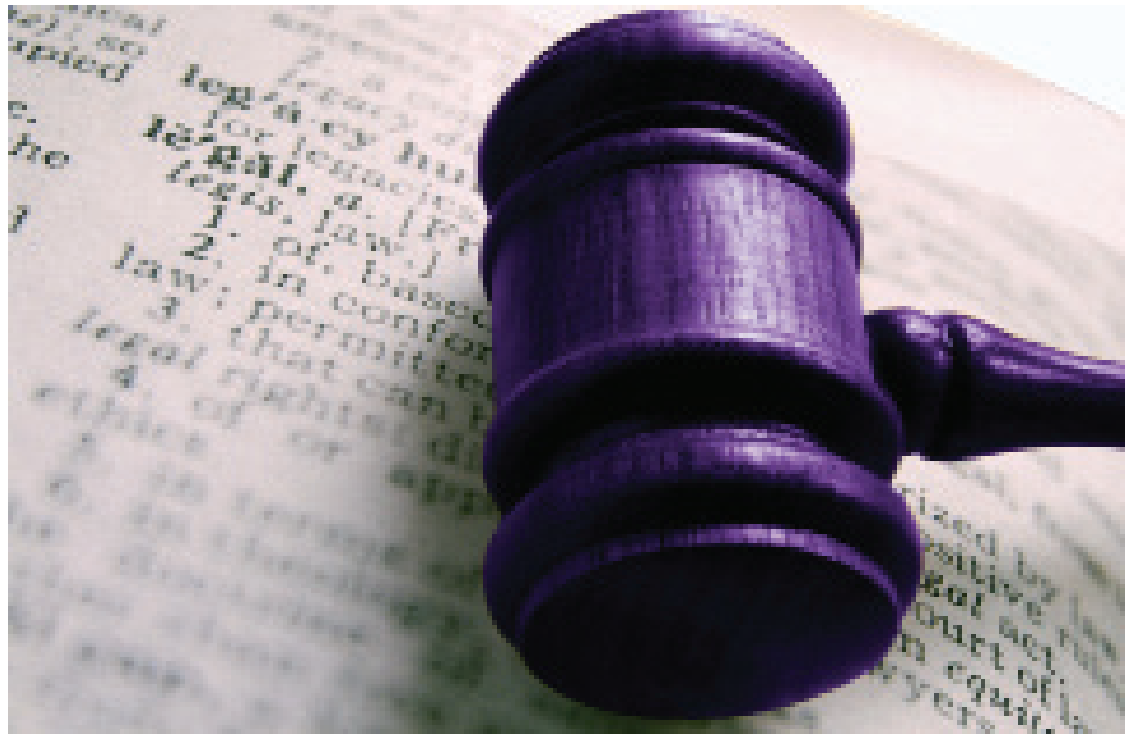

\section{REGULATIONS}

\section{॥ No way out}

In July 2012, The US District Court in Washington, DC ruled that the FDA has the authority to regulate autologous stem cell therapies. This ruling means that from a legal point of view stem cells are treated as drugs if they have been subjected to more than minimal manipulation. The court's ruling was on a legal challenge brought by Regenerative Sciences, CO, USA (www.regenexx.com) when the FDA sought an injunction to take their product Regenexx ${ }^{\mathrm{TM}}$ off the market. The company claimed that the FDA should not be involved in monitoring and regulating Regenexx because the cells were minimally manipulated and all processing has been done in

\section{$\mathbf{6}$ This ruling means that \\ from a legal point of view stem cells are treated as drugs if they have been subjected to more than minimal manipulation.}

Colorado. Therefore, the procedure should be considered routine medical practice and be subjected to state law. To avoid strict FDA regulatory monitoring, it is thought that, following this ruling, US stem cell companies offering similar type of services may move to states with lesser regulations.

\section{CAPITAL MARKET AND FINANCES}

\section{„ Successful ride on government funding}

Privately held, venture capital-backed Cellerant Corporation, CA, USA (www.cellerant.com), continued its successful ride on government funding. In September 2011, the Company received US $\$ 16.7$ million by the Biomedical Advanced Research and Development Authority in the
Office of the Assistant Secretary for Preparedness and Response of the Department of Health and Human Services, for the advanced development of CLT-008, a first-inclass, allogeneic, cell-based therapy for the treatment of acute radiation syndrome. This funding is in addition

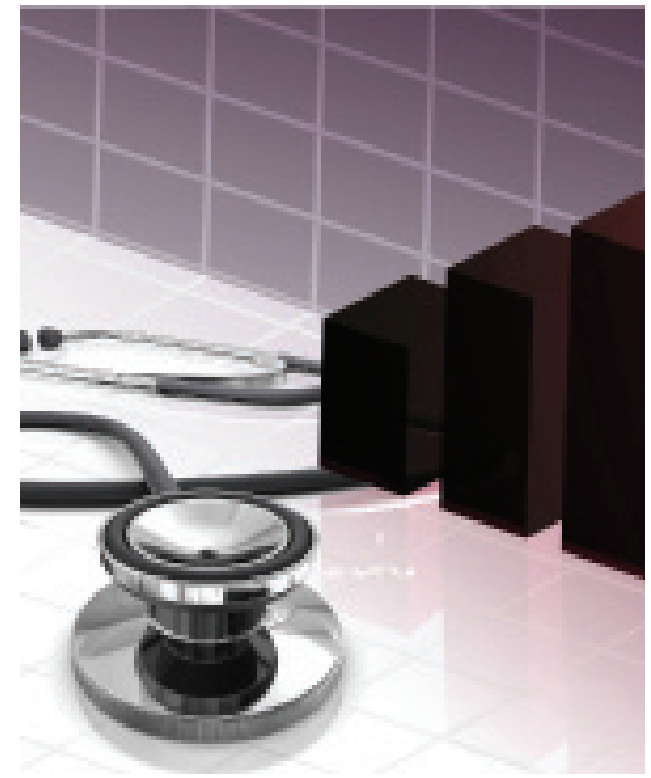


to the existing contract valued at up to US\$153.2 million previously awarded in September 2010. Under the terms of this revised contract, Cellerant will receive up to $\$ 80$ million in the 2-year base period of performance and up to an additional US\$89.9 million in 3 option years, if exercised by Biomedical Advanced Research and Development Authority, bringing the total value of the contract to US $\$ 169.9$ million.
Cellerant's CLT-008 cell therapy product contains only early- to late-stage myeloid progenitor cells, which have lost the ability to self-renew and are restricted to creating mature myeloid cells: red blood cells, platelets, granulocytes and macrophages. They cannot create lymphoid cells, including the $T$ cells that cause GVHD. Once infused, CLT-008 myeloid progenitor cells create a burst of mature cells and then die and clear out of the system in approximately 45 days.

\title{
» Xeno-cell therapy attracting investments
}

\begin{abstract}
Australia/New Zealand-based Life Cell Technologies (www.lctglobal. com), secured a major pharmaceutical partner, Japanese giant Otsuka Pharmaceutical Factory (www. otsukakj.jp/en/), for co-development of its product DIABECELL ${ }^{\circledR}$ through Phase II and other pivotal studies, aiming for marketing by 2016. Life Cell and Otsuka formed a joint venture in November 2011, Diatranz Otsuka Ltd, with each partner owning a $50 \%$ share in the new company. With development funding secured for DIABECELL, Life Cell is poised to further develop its second xeno-cell

therapy product NTCELL ${ }^{\circledR}$ aimed for treatment of Parkinson's disease. Treatment with NTCELL involves transplanting pig choroid plexus cells into the brain. Choroid plexus cells secrete neurotrophic factors vital to the health and survival of brain tissue. The goal of the transplanted cells is to boost neurotrophin production and so help to protect, repair and possibly regenerate brain and nerve tissue. Both DIABECELL and NTCELL are encapsulated with IMMUPELTM, Life Cell's proprietary encapsulating technology, eliminating the need for immunosuppressant drugs.
\end{abstract}

66 With development funding secured for DIABECELL ${ }^{\circledR}$, Life Cell is poised to further develop its second xeno-cell therapy product NTCELL ${ }^{\circledR}$ aimed for treatment of Parkinson's disease. 99

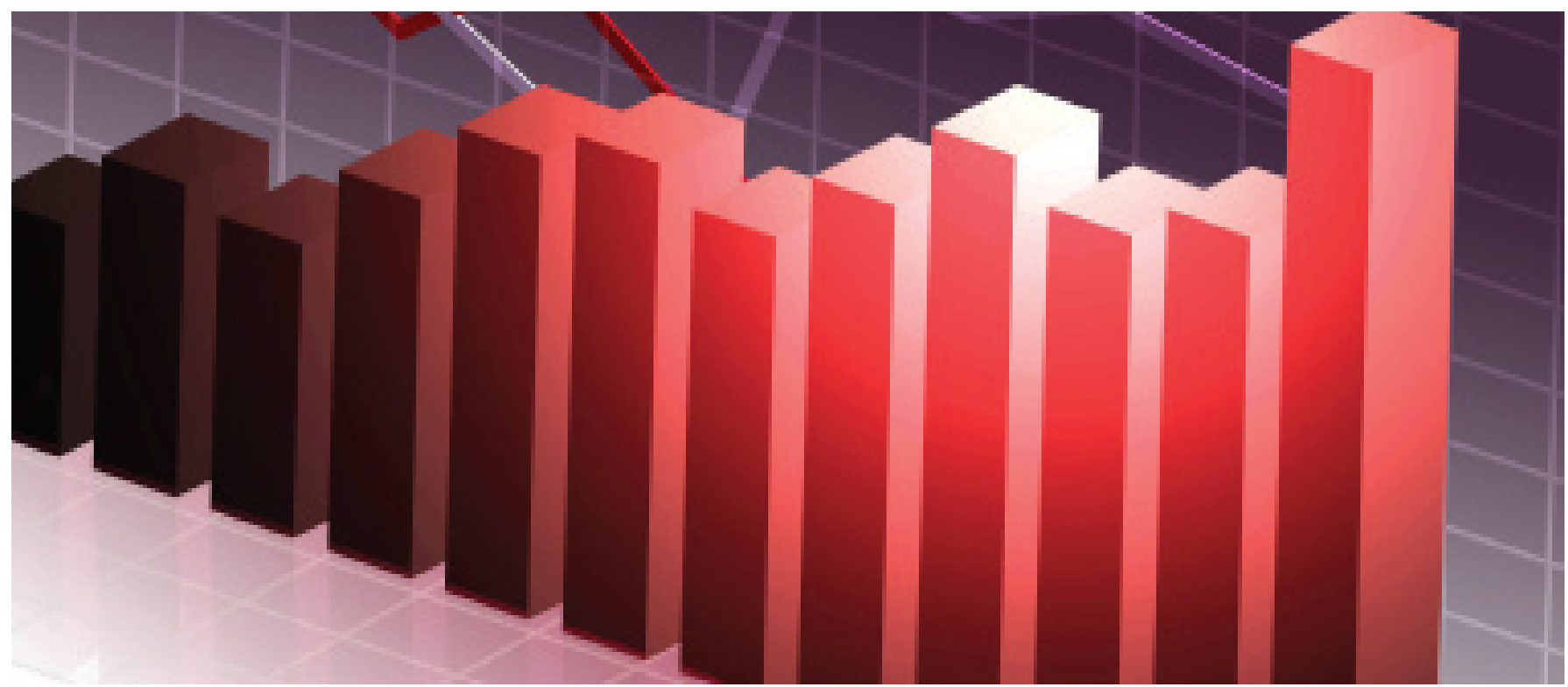

